\title{
Cinética de absorção de fósforo em soja transgênica após a aplicação de glyphosate $^{1}$
}

\author{
Kinetics of phosphorus uptake in transgenic soybeans after glyphosate application
}

\author{
Lucas Perim $^{2}$, Maryara Buriola Prando ${ }^{3}$, Ciro Antonio Rosolem ${ }^{4}$
}

\begin{abstract}
Resumo - Há indicações de que o glyphosate pode interferir na nutrição fosfatada da soja. Desta forma, o presente trabalho teve como objetivo estudar a absorção e alocação de fósforo (P) em soja após a aplicação de glyphosate. Foram realizados dois experimentos conduzidos em casa-de-vegetação em delineamento experimental de blocos inteiramente casualisados. $\mathrm{O} 1^{\circ}$ experimento avaliou-se o glyphosate nas dosagens de 0,$0 ; 1,5 ; 3,0 ; 6,0$ e $12,0 \mathrm{~g} \mathrm{ha}^{-1}$ e o $2^{\circ}$ experimento avaliou-se o glyphosate nas dosagens de 0,$0 ; 200,0 ; 400,0$ e 800,0 $\mathrm{g} \mathrm{ha}^{-1}$. O glyphosate foi aplicado aos 21 dias após a emergência das plantas via foliar na variedade de soja 'Valiosa RR'. Em seguida as plantas foram cultivadas em solução nutritiva utilizando-se a técnica de exaustão da solução. Após o ensaio de exaustão, as plantas foram coletadas para a determinação da massa de seca e os teores $\mathrm{P}$, na parte aérea e raízes. Embora não tenha sido possível determinar parâmetros da cinética de absorção, não foi verificado efeito estimulante na absorção de P pela soja, após a aplicação de baixas dosagens do glyphosate, ou efeito depressivo, quando aplicado em dosagens compatíveis as recomendadas para controle de plantas daninhas.
\end{abstract}

Palavras-chave: Herbicida; fósforo; absorção; Glycine max.

\begin{abstract}
There are indications that glyphosate could affect the phosphorus nutrition of soybean. Thus the present study was to evaluate $\mathrm{P}$ uptake absorption and allocation in soybean after glyphosate application. Two experiments were conducted in green-house in randomized complete block. The $1^{\text {st }}$ experiment evaluated the glyphosate at 0,$0 ; 1,5 ; 3,0 ; 6,0$ and $12,0 \mathrm{~g} \mathrm{ha}^{-1}$ and the $2^{\text {nd }}$ experiment evaluated the glyphosate at 0,$0 ; 200 ; 400$ and $800 \mathrm{~g} \mathrm{ha}^{-1}$. Glyphosate was applied at 21 days after plant emergence in foliar soybean variety 'Valiosa RR'. Then the plants were grown in nutrient solution using the technique of exhaustion of the solution. After the exhaustion test, the plants were collected for determination of dry matter and P contents in shoots and roots. Although it was not possible to determine the kinetics of absorption, was not observed stimulatory effect of $\mathrm{P}$ uptake in soybean after applied at low rates or depressant effect when applied at compatible rates with those recommended for weed control.
\end{abstract}

Key-words: Herbicide; phosphorus; absortion; Glycine max.

\footnotetext{
${ }^{1}$ Recebido para publicação em 13/05/2011, e aceito em 20/08/2011.

${ }^{2}$ Eng. Agr. MSc Doutorando, Dep. de Produção Vegetal, FCA/Unesp, Botucatu-SP, lperim@ fca.unesp.br.

${ }^{3}$ Eng.-Agr . Dep. de Produção Vegetal, FCA/Unesp, Botucatu-SP.

${ }^{4}$ Prof. Titular do . Dep. de Produção Vegetal, FCA/Unesp, Botucatu-SP, rosolem@ @ fa.unesp.br.
}

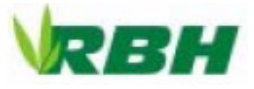




\section{Introdução}

No Brasil, a área cultivada com soja resistente ao glyphosate (RR) alcançou na safra 2010/2011 cerca de $80 \%$ da área total plantada da cultura (CONAB, 2010), e continua aumentando significativamente. A cada ano, empresas de biotecnologia investem bilhões de dólares para o desenvolvimento de variedades resistentes a herbicidas (Zobiole et al., 2010). No entanto, com o aumento do uso da tecnologia da soja Roundup Ready ${ }^{\circledR}$, muitos agricultores têm notado que alguns cultivares RR apresentam injúrias visuais logo após a aplicação do glyphosate em pós-emergência (Santos et al., 2007; Zablotowicz \& Reddy, 2007).

O glyphosate (N-phosphonomethylglycine) é um herbicida não-seletivo aplicado em pós-emergência, cuja eficácia é dependente de processos como a retenção da molécula na superfície foliar, a penetração foliar, a translocação na planta até o sítio de ação e a inibição da enzima-alvo, a 5-enolpiruvilchiquimato-3-fosfato-sintetase

(EPSPs)

(Kirkwood \& Mckay, 1994). Denis \& Delrot (1993) e Morin et al, (1997) demonstraram que proteínas transportadoras de grupos fosfatos, que estão presentes na membrana plasmática da Vicia faba e Catharanthus roseus, facilitaram a absorção de glyphosate.

De acordo com o estudo de Godoy (2007), a deficiência de fósforo é um dos maiores estresses abióticos que afetam o crescimento das plantas, especialmente em solos tropicais e onde as plantas podem reduzir essa deficiência por meio da coordenação da expressão dos genes envolvidos no alívio do estresse. A mobilização do fosfato dentro da planta é um complexo processo que requer numerosos transportadores para a sua absorção e translocação.

O fósforo é um elemento limitante da produção agrícola, embora esteja em uma quantidade relativamente alta no solo, não é encontrado na forma lábil ou ao alcance da rizosfera. Sendo assim, se faz necessária a aplicação de fósforo na forma inorgânica $(\mathrm{Pi})$ no solo para que se alcance a produtividade esperada. A mobilidade do fósforo inorgânico no solo é muito baixa em relação ao total aplicado ao solo. Segundo Rosolem (1982), as plantas de soja deficientes em $\mathrm{P}$ possuem de início as folhas mais velhas e intermediárias com coloração mais escura as quais evoluem para clorose generalizada que caminha da ponta para a base. Os sintomas são acentuados nos estádios de floração e enchimento dos grãos.

A cinética de absorção indica que o transporte do componente saturável do glyphosate é competitivamente inibido por fosfato ou ácido fosfonofórmico (Hetherington et al., 1998; Denis \& Delrot, 1993), que são potentes inibidores do transporte de fosfato em células isoladas de feijão (Brecke \& Duke, 1980). Pipke (1987) relatou que o fosfato inibe a absorção de glyphosate em Arthrobacter, uma bactéria capaz de metabolizar glyphosate. Esses estudos permitem concluir que a absorção de glyphosate pode ser mediada por transportadores de fosfato da membrana plasmática, que reconhecem o grupo fosfato da molécula de glyphosate. Fitzgibbon \& Braymer (1988) relatam que em trabalhos com Pseudomonas sp. Strain PG2982, a absorção de glyphosate foi induzida pela deficiência de fósforo e concluíram que o sistema transportador de fosfato, que possui ampla especificidade de substrato, pode ser responsável por esta absorção. Apesar de seu amplo uso, relativamente pouco se sabe sobre o transporte de glyphosate nas plantas. Da mesma forma que os conhecimentos sobre o transporte de $\mathrm{P}$ nas plantas é limitado (Versaw $\&$ Harrison, 2002).

Em muitas circunstancias, o glyphosate pode ser benéfico para as plantas cultivadas, desde que aplicado em baixas doses. O primeiro exemplo é o uso de doses em torno de 
48 a $180 \mathrm{~g} \mathrm{ha}^{-1}$, como maturador em cana de açúcar. A colheita da cana é realizada algumas semanas após aplicação e pode voltar a crescer para produzir a segunda ou terceira colheita (Velini et al., 2006).

O objetivo deste trabalho foi avaliar o efeito de doses de glyphosate, sobre o crescimento e absorção de fósforo pela cultura da soja.

\section{Material e métodos}

Os experimentos foram conduzidos na casa-de-vegetação, do Departamento de Produção Vegetal da Faculdade de Ciências Agronômicas, UNESP-Botucatu/SP. Foram realizados dois experimentos, no delineamento experimental em blocos inteiramente casualisados, com quatro repetições. $\mathrm{O} \quad 1^{\mathrm{o}}$ experimento avaliou-se o glyphosate nas dosagens de 0,$0 ; 1,5 ; 3,0 ; 6,0$ e $12,0 \mathrm{~g} \mathrm{ha}^{-1}$ e o $2^{\circ}$ experimento avaliou-se o glyphosate nas dosagens de 0,$0 ; 200,0 ; 400,0$ e 800,0 $\mathrm{g} \mathrm{ha}^{-1}$.

As sementes da cultivar de soja Valiosa RR (transgênica, com tolerância ao glyphosate) foram colocadas para germinar em câmara de germinação, em papel umedecido com $\mathrm{CaSO}_{4}$, na temperatura de $25^{\circ} \mathrm{C}$ para obtenção de plântulas, e após seis dias, as plântulas foram selecionadas quanto à sanidade e uniformidade. O substrato utilizado para o crescimento e desenvolvimento das plantas foi à solução de Hoagland (1938) cuja concentração variou nas duas primeiras semanas de condução do experimento. $\mathrm{Na}$ primeira semana de desenvolvimento das plantas foi empregada a solução diluída a 1/10. Na segunda semana a solução foi diluída a 1/2. E a partir da terceira semana empregou-se a solução completa de Hoagland.

As plântulas foram transferidas para vasos plásticos, os quais eram compostos por 3,5 L de solução de Hoagland. Esta solução foi constantemente aerada e o volume mantido constante com variação máxima de 5\%. As soluções tinham seus valores de $\mathrm{pH}$ monitorados e mantidos em torno de 5,5 por meio de correções usando-se $\mathrm{HCl}$ ou $\mathrm{NaOH}$. A solução foi renovada quando se apresentava $\mathrm{pH} 7,0$. Foram cultivadas 2 plantas por vaso, formando assim a unidade experimental.

Ao $21^{\circ}$ dia após o início do cultivo foi aplicado o herbicida glyphosate via foliar, nas dosagens indicadas. Aos 3 dias após a aplicação do herbicida (DAA), as plantas de soja foram submetidas ao ensaio de exaustão. Para tanto, as soluções dos vasos foram trocadas omitindo-se o fósforo $(\mathrm{P})$, e as plantas foram ali deixadas por 24 horas. Pretendia-se com isso que o $\mathrm{P}$ presente no espaço livre aparente das células das raízes, retornasse a solução nutritiva, por diferença de concentração. A seguir, foi adicionada a solução nutritiva $30 \mu \mathrm{M}$ de $\mathrm{P}$, onde as plantas permaneceram por duas horas para se obter as condições de estado estacionário de absorção requerida para aplicação do modelo cinético de absorção (Epstein \& Hagen, 1952). Logo após, amostras de $5 \mathrm{~mL}$ da solução nutritiva foram tomadas aos $0,15,30,45,90,180,360,720$, 1440 minutos após a instalação dos tratamentos, somando-se 24 horas de amostragem.

Ao término do período de exaustão as plantas foram coletadas e separadas em parte aérea e raiz. As raízes foram enxugadas em papel toalhas e pesadas para obtenção da massa de massa fresca $(\mathrm{g})$, que de acordo com Hallmark et al. (1984), pode ser representada pelo volume radicular. As partes aéreas foram também pesadas para determinação da massa fresca e juntamente com as raízes foram colocadas para secar em estufa de circulação forçada de ar a $60^{\circ} \mathrm{C}$ até atingirem peso constante, para então determinarmos à massa seca da parte aérea e das raízes (g).

Estes parâmetros são necessários para se expressar os resultados da cinética, ou seja, a 
velocidade máxima de absorção $\left(\mathrm{V}_{\max }\right)$ e o $\mathrm{Km}$ por unidade de massa da raíz. No cálculo dos parâmetros foi empregado o programa Cinética 1.2 (Ruiz \& Fernandes, 1992), onde os valores de $K_{m}$ e $V_{\text {máx }}$, foram obtidos considerando-se a massa radicular como base de cálculo. Os modelos matemáticos e respectivas equações das curvas de exaustão foram selecionados de acordo com critérios apontados por Ruiz (1985). Os valores de $C_{\min }$ serão considerados como sendo a concentração de $\mathrm{P}$ presente nas amostras de solução após 24 horas do início do período das amostragens.

\section{Resultados e discussão}

De acordo com a Tabela 1, observou-se que independentemente das dosagens de glyphosate utilizadas nos experimentos a cultivar de soja 'Valiosa RR' não apresentou resposta aos tratamentos empregados quanto à massa seca da parte aérea e radicular. Efeitos negativos no acúmulo de biomassa ocorrem provavelmente devido aos efeitos aditivos da diminuição da taxa fotossintética e da redução na concentração dos nutrientes na parte aérea (Zobiole et al., 2010). Da mesma maneira, outros autores, utilizando $1.680 \mathrm{~g} \mathrm{ha}^{-1}$ e $6.300 \mathrm{~g}$ ha ${ }^{-}$de glyphosate, encontraram reduções na biomassa da parte aérea e de raízes de soja RR (Reddy et al., 2000; King et al., 2001). Esses resultados corroboram com os encontrados por Bott et al. (2008), os quais observaram que a aplicação do glyphosate na soja RR reduziu significativamente a biomassa e a elongação da raiz.

Velini et al. (2008) ressaltaram que o glyphosate aplicado em altas dosagens inibiu o crescimento de espécies não transgênicas, como soja, milho, trapoeraba e pinus.
Entretanto, quando aplicado em dosagens baixas $\left(1,8\right.$ a $36,0 \mathrm{~g}$ ha $\left.^{-1}\right)$, o glyphosate proporcionou estímulo entre 50 e $100 \%$ no crescimento de folha, caule e raiz, nas espécies $C$. benghalensis, E. grandis e P. caribea. Da mesma forma, Cedergreen (2008) afirma que o glyphosate pode estimular o acúmulo de biomassa em plantas de Hordeum vulgare em torno de $25 \%$, quando aplicadas dosagens que correspondem de 5 a $10 \%$ da recomendada.

O teor de fósforo tanto na parte aérea ou na raiz de ambos experimentos, não apresentou resposta aos tratamentos empregados como pode ser observado na Tabela 1. Os resultados corroboram com Santos et al. (2007), onde plantas de eucalipto tratadas com glyphosate não mostraram reduções nos teores foliares de P. Tal fato comprova a indução da expressão de genes transportadores de fósforo em condições de baixa disponibilidade deste elemento (Liu et al., 1998; Daram, 1998). O que tem sido aceito é que os genes induzidos em condições de baixa disponibilidade de fósforo são os genes transportadores de alta afinidade e que esses mesmos seriam responsáveis apenas pela absorção radicular. Genes dos transportadores de fósforo de baixa afinidade é que seriam responsáveis pelo movimento do fósforo dentro da planta. 
Tabela 1. Médias da matéria seca e do teor de fósforo das plantas de soja 'Valiosa RR', submetidas à diferentes doses de glyphosate. Botucatu-SP, 2010.

\begin{tabular}{ccccc}
\hline \multirow{2}{*}{$\begin{array}{c}\text { Dosagens de } \\
\text { Glyphosate } \\
\left(\mathrm{g} \mathrm{e.a.} \mathrm{ha}^{-1}\right)\end{array}$} & \multicolumn{2}{c}{ Masas Seca $(\mathrm{g})$} & \multicolumn{2}{c}{ Teor de Fósforo $(\mathrm{g} / \mathrm{Kg})$} \\
\cline { 2 - 5 } & Parte Aérea & Raíz & Parte Aérea & Raíz \\
\hline 0 & 15,12 & 2,45 & 5,51 & 13,48 \\
1,5 & 15,67 & 2,43 & 5,55 & 13,83 \\
3 & 13,61 & 2,56 & 5,64 & 15,81 \\
6 & 14,91 & 2,36 & 6,01 & 16,61 \\
12 & 13,70 & 2,16 & 5,78 & 14,70 \\
\hline 0 & 14,77 & 2,48 & 5,63 & 14,48 \\
200 & 14,18 & 2,51 & 5,38 & 12,29 \\
400 & 15,31 & 2,61 & 5,66 & 13,67 \\
800 & 13,94 & 2,20 & 5,79 & 14,69 \\
\hline
\end{tabular}

França et al. (2010) observaram que o teor de P nas folhas do cultivar de café Topázio apresentou-se menor quando comparado ao dos demais cultivares estudados, nas dosagens de 230,4 e 460,8 $\mathrm{g} \mathrm{ha}^{-1}$ de glyphosate. Godoy (2007), ao avaliar o efeito do glyphosate na absorção de fósforo em soja convencional e transgênica observou que dosagens entre $1,8 \mathrm{e}$ $3,6 \mathrm{~g} \mathrm{ha}^{-1}$ de glyphosate foram as que promoveram maior conteúdo de fósforo total na soja convencional. Cakmak et al. (2009) também observaram que, em soja convencional que as dosagens de glyphosate 0,864, 2,88 e $8,64 \mathrm{~g} \mathrm{ha}^{-1}$ promoveram incrementos nos teores de fósforo em folhas jovens. Em folhas velhas não houve diferença significativa para os teores de fósforo.

Os teores de fósforo presente na solução de Hoagland em função do tempo encontram-se apresentadas nas Figuras 1 ( $a, b$, c e d). Observa-se que para ambos experimentos as dosagens de $\mathrm{P}$ na solução no tempo zero foi inferior as dosagens nos tempos de 15 e 30 minutos. Nos intervalos de tempo 45 a 90 minutos o teor de $\mathrm{P}$ da solução apresentase baixo, todavia nos tempos sequentes de 180 e 360 minutos estes valores novamente apresentam-se mais elevados. E novamente nos dois intervalos finais de 720 e 1440 minutos estes valores voltam a decrescer. 

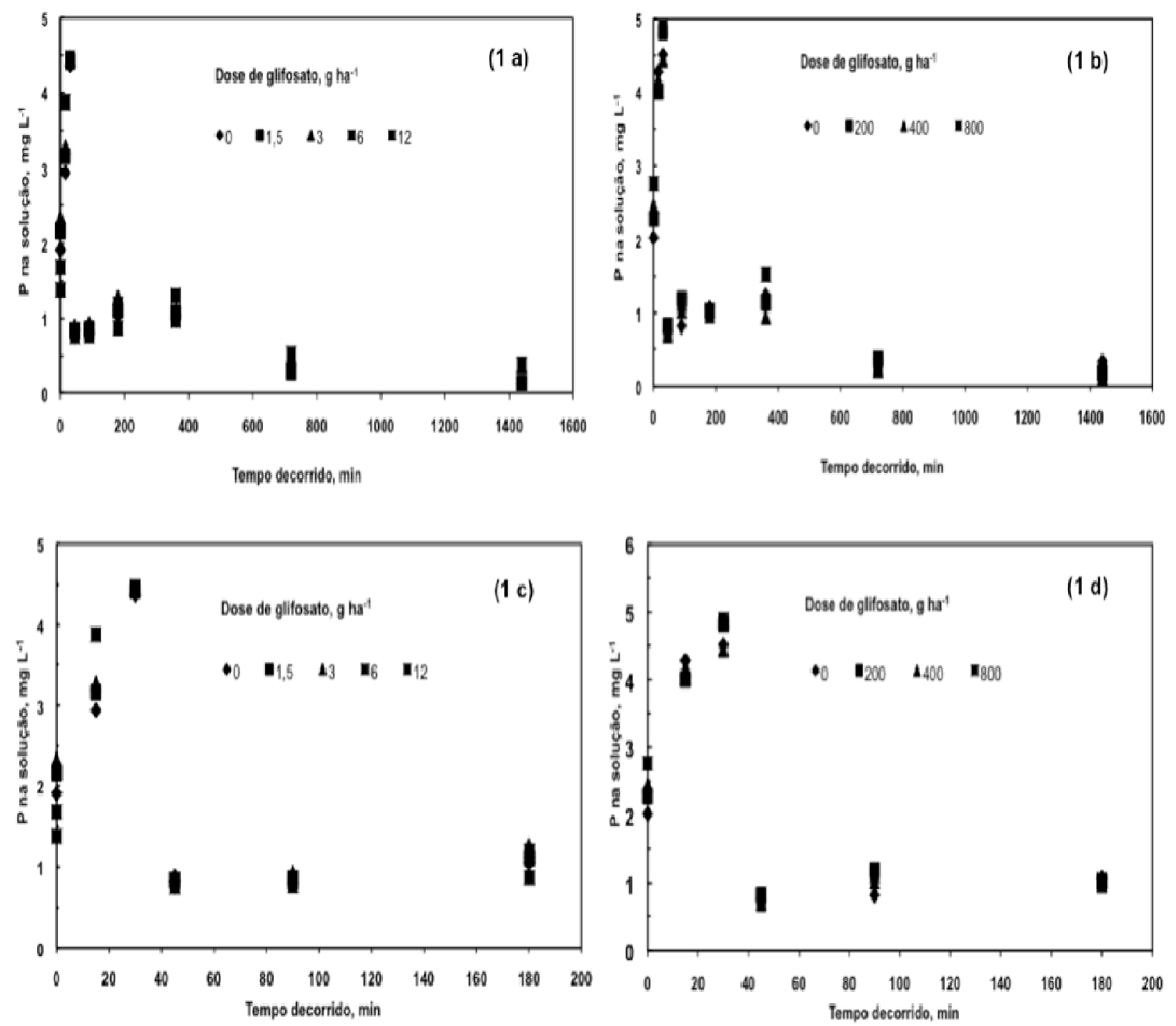

Figura 1: (a)Teores de P na solução do solo em função de baixas doses de glyphosate, (b)Teores de P na solução do solo em função de dosagens recomendadas de glyphosate, (c)Exaustão do P da solução nutritiva nos primeiros 180 minutos em função da aplicação de baixas dosagens de glyphosate, (d)Exaustão do $\mathrm{P}$ da solução nutritiva nos primeiros 180 minutos em função de dosagens recomendadas de glyphosate, aplicado na soja 'Valiosa RR'. Botucatu-SP, 2010.

Esse padrão de comportamento não permitiu que os resultados se ajustassem ao programa cinética, pois fugiram completamente do padrão de exaustão esperado. Isso pode ter ocorrido em função de falta de ajuste nos teores de $\mathrm{P}$ da solução de exaustão, ou ainda, de tempo muito curto sem $\mathrm{P}$ na solução, para que todo o $\mathrm{P}$ do espaço livre aparente voltasse à solução.

Entretanto, não foram observados diferenças significativas no padrão de exaustão de P da solução, indicando não haver efeito do 
glyphosate no processo. Embora não tenha sido possível a determinação do $\mathrm{V}_{\text {máx }}$ (velocidade máxima de absorção) e do $\mathrm{K}_{\mathrm{m}}$ (que indica a afinidade do carregador pelo íon). $\mathrm{O} \mathrm{C}_{\text {mín }}$ (concentração mínima da solução em que há absorção), representado na Figura 1 pelos pontos obtidos aos 150 minutos, não foi afetado pela aplicação do glyphosate. Dessa forma, não se confirmou a hipótese de que poderia haver interação da aplicação do glyphosate com a nutrição fosfatada da soja porque seriam medidas pelo mesmo carregador.

Segundo a literatura a interação ocorreria em baixas concentrações de $\mathrm{P}$ (Godoy, 2007), ou seja, em concentração de $\mathrm{P}$ na solução próximas ao $\mathrm{C}_{\mathrm{mín}}$, o qual não foi observado no presente trabalho.

\section{Conclusões}

A aplicação de glyphosate sobre a cultivar de soja Valiosa $\mathrm{RR}^{\circledR}$, não interferiu na absorção de $\mathrm{P}$ pela soja.

\section{Referências}

BRECKE, B.J.; DUKE, W.B. Effect of Glyphosate on Intact Bean Plants (Phaseolus vulgaris L.) and Isolated Cells. Plant Physiology, v.66, n.4, p.656-659,1980.

BOTT, S. et al. Glyphosate-induced impairment of plant growth and micronutrient status in glyphosate-resistant soybean (Glycine $\max$ L.). Plant Soil, v.312, n.1-2, p.185-194, 2008.

CAKMAK, I. Glyphosate reduced seed and leaf concentrations of calcium, manganese, magnesium and iron in non-glyphosate resistant soybean. European Journal Agronomy, v.31, n.1, p.114-119, 2009.

CEDERGREEN, N. Herbicides can stimulate plant growth. Weed Research, v.48, n.5, p.429-438, 2008.
Companhia Nacional de Abastecimento. Acompanhamento de safra brasileira: grãos, quarto levantamento, janeiro 2011 / Companhia Nacional de Abastecimento. Brasília : Conab, 2011. n39 p.

DARAM, P. et al. Functional analysis and cellspecific expression of a phosphate transporter from tomato. Planta, v.206, n.2, p.225-233, 1998.

DENIS, M.H.; DELROT, S. Carrier-mediated uptake of glyphosate in broad bean (Vicia faba) via a phosphate transporter. Physiologia Plantarum, v. 87, n.1, p.569-75, 1993.

EPSTEIN, E \& HAGEN, C.E. A kinetic study of the absorption of álcali cations by barley roots. Plant Physiology, v.27, n.2, p.457-474. 1952.

FITZGIBBON, J.; BRAYMER H.D. Phosphate starvation induces uptake of glyphosate by Pseudomonas sp. Strain PG 2982. Apply Environmental Microbiology, v.54, n.3, p.1886-1888, 1988.

FRANÇA, A.C et al. Teores de nutrientes em cultivares de café arábica submetidos à deriva de glyphosate. Planta Daninha. v.28, n.4, p.877-885, 2010.

GODOY, M.C. Efeitos do glyphosate sobre o crescimento e absorção de fósforo pela soja. 2007. 42f. Dissertação (Mestrado em Agronomia). Faculdade de Ciências Agronômicas da UNESP - Campus de Botucatu, 2007.

HALLMARK, W.B., BARBER, S.A. Root growth and morphology, nutrient uptake and nutrient status or early growth of soybeans as affected by soil P and K. Agronomy Journal, v. 76, n.2, p. 209-212, 1984.

HETHERINGTON， P.R.; MARSHALL,G.; KIRKWOOD, R.C.; WARNER, J.M. Absorption and efflux of glyphosate by cell suspensions. Journal of Experimental Botany, v.49, n.320, p. 527-533, 1998. 
HOAGLAND, D.R.; ARNON, D.I. The water culture method for growing plants without soil. California Agriculture 1 Experimental Station. Circular 347, 1938.

KIRKWOOD, R. C.; MCKAY, I. Accumulation and elimination of herbicides in select crop and weed species. Pesticides Science, v.42, n.1, p.241-248, 1994.

KING, C.A.; PURCELL, L.C.; VORIES. E.D. Plant growth and nitrogenase activity of glyphosate tolerant soybean in response to foliar glyphosate applications. Agronomy Journal, v.93, n.2, p.179-186, 2001.

LIU, C.; TRIEU, A.T.; BLAYLOCK, L.A.; HARRISON, M.J. Cloning and charaterization of two phosphate transporters from Medicago truncatula roots: regulation in response to phosphate and to colonization by arbuscular mycorhizal (AM) fungi. Molecular Plant Microbe Interactions, v.11, n.2, p.14-22, 1998.

MORIN F.; VERA, V.; NURIT F.; TISSUT, M.; MARIGO, G. Glyphosate uptake in Catharanthus roseus cells: Role of a phosphate transporter. Pesticide Biochemistry Physiology, v.58, n.2, p. 13-22, 1997.

PIPKE, R.; SCHULZ, A.; AMRHEIN, N. Uptake of gluphosate by an rathrobacter sp. Applied and Environmental Microbiology, v.53, n.1, p. 974-978, 1987.

REDDY, K. N.; HOAGLAND, R. E.; ZABLOTOWICZ, R. M. Effect of glyphosate on growth, chlorophyll content and nodulation in glyphosate-resistant soybeans (Glycine max) varieties. Journal of New Seeds, v.2, n.1, p.37-52, 2000.

ROSOLEM, C.A. Nutrição mineral $\mathbf{e}$ adubação da soja. 2.ed. Piracicaba, Potafós, 1982. 80p. (Boletim, 6).

RUIZ, H.A. Estimativa dos parâmetros cinéticos Km e Vmáx. Por uma aproximação gráfico matemática. Revista Ceres, v.32, n.179, p.79-84, 1985.

RUIZ, H.A., FERNANDES FILHO, E.I. Cinética: software para estimar constantes Vmáx e Km da equação de Michaelis-Menten. In: Reunião brasileira de fertilidade do solo e nutrição de plantas, 20, 1992. Anais... Piracicaba: SBCS, 1992. p.124-5.

SANTOS, J. B. et al. Efeito de formulações na absorção e translocação do glyphosate em soja transgênica. Planta Daninha, v.25, n.2, p.381388, 2007.

VELINI, E. D. et al. Glyphosate applied at low doses can stimulate plant growth. Pest Management Science, v.64, n.4, p.489-496, 2008.

VELINI, E.D.; ALVES, E.; CORREA, M.R.; CORREA, T.M.; QUEIROZ, C.A.S.; SOUZA, R.T. Sub-dose de Glyphosate estimulam o crescimento de plantas daninhas e cultivadas. In: Congresso Brasileiro de Plantas Daninhas, 25., 2006, Brasília. Resumos... SBCPD: Brasília, p.210. 2006.

VERSAW, W.K.; HARRISON, M.H. A chloroplast phosphate transporter, PHT2;1, influences allocation of phosphate within the plant and phosphate-starvation responses. Plant Cell, v.14, n.1 p.1751-1766, 2002.

ZABLOTOWICZ, R. M.; REDDY, K. N. Nitrogenase activity, nitrogen content, and yield responses to glyphosate in glyphosateresistant soybean. Crop Protection, v. 26, n.3, p. 370-376, 2007.

ZOBIOLE, L. H. S. et al. Glyphosate reduces shoot concentration of mineral nutrients in glyphosate-resistant soybeans. Plant Soil, v.328, n.1, p.57-69, 2010. 